\title{
Predictors of choosing life-long screening or prophylactic surgery in women at high and moderate risk for breast and ovarian cancer
}

\author{
J. R. J. De Leeuw $\cdot$ M. J. van Vliet \\ M. G. E. M. Ausems
}

Published online: 14 March 2008

(C) The Author(s) 2008

\begin{abstract}
The aim of this study is to summarize published empirical data describing the predictors of adhering to screening practices and choosing to have prophylactic surgery in women at increased risk for breast and ovarian cancer. Pubmed, Psychinfo and Cinahl databases were searched to identify studies on the predictors of adherence to breast and ovarian cancer screening and predictors of having a prophylactic mastectomy or salpingo-oophorectomy. We found 37 empirical studies that met our inclusion criteria. The main predictors of the use of preventive measures are related to DNA test results, socio-demographic characteristics, and psychological outcome measures. It is concluded that there is no unequivocal relationship between age, education, risk perception, or anxiety and adherence to breast and ovarian cancer screening practices. Worrying about cancer is associated with a higher adherence to screening practices.
\end{abstract}

Keywords Surveillance - Breast cancer - Ovarian cancer · Prophylactic surgery $\cdot$ BRCA carrier $\cdot$ Predictors

$\begin{array}{ll}\text { Abbreviations } \\ \text { BPM } & \text { Bilateral prophylactic mastectomy } \\ \text { BSE } & \text { Breast self examination } \\ \text { FDR } & \text { First-degree relative } \\ \text { PM } & \text { Prophylactic mastectomy }\end{array}$

J. R. J. De Leeuw $(\varangle) \cdot$ M. J. van Vliet

Department of Nursing Science, University Medical Center Utrecht, P.O. Box 80.036, 3508 Utrecht, TA, The Netherlands e-mail: J.R.J.deleeuw@umcutrecht.nl

M. G. E. M. Ausems

Department of Medical Genetics, University Medical Center Utrecht, Utrecht, The Netherlands
CPM Contralateral prophylactic mastectomy

BPSO Bilateral prophylactic salpingo-oophorectomy

\section{Introduction}

Breast cancer is one of the most important causes of death in women and those with a family history of breast cancer are at increased risk of the disease [54]. The risk is two to three times higher in women who have a first-degree relative (FDR) with breast cancer [13], or even higher if the relative had bilateral premenopausal breast cancer or breast cancer under the age of 40 years [48], when compared with women who have no family history of breast cancer. Increasingly, women at familial risk for breast cancer are being targeted for cancer prevention and monitoring. It is estimated that of all breast cancer patients, $5-10 \%$ carry inherited autosomal dominant mutations [25]. Hereditary breast cancer is also strongly associated with the occurrence of ovarian cancer in a family and with multiple cases of breast cancer, particularly if these were cases of earlyonset [42].

Since the identification of two breast cancer susceptibility genes, BRCA1 and BRCA2, genetic testing has been incorporated into the practice of oncology [42]. Mutations in the BRCA1 and BRCA2 genes are associated with an increased risk for breast and ovarian cancer [5]. When a woman is identified as a mutation carrier, specific screening practices and/or prophylactic surgery become options to consider [10]. To detect early development of cancer in women at high risk for breast cancer, it is important that they are alert to suspicious symptoms, that they perform frequent self-examination of their breasts (BSE), and that they have regular mammography or breast MRI and 
clinical breast examinations (secondary prevention) [42]. Screening for ovarian cancer includes semi-annual transvaginal ultrasound and CA-125 measurement [10]. Some women opt for prophylactic surgery (primary prevention) to prevent the development of cancer; it seems to reduce the risk of breast and ovarian cancer developing [15, 37].

Earlier studies have shown that women at risk for breast cancer often do not adhere to the recommended guidelines for a monthly breast self-examination [24] or mammographic screening [30], and that women with comparable risks for cancer may vary greatly in whether they opt to have prophylactic surgery or not $[38,50,51]$. In the near future, more women will be identified as carriers of a BRCA1 or BRCA2 mutation and will therefore know they carry a high risk gene for breast and ovarian cancer. From a preventive point of view, it is important to know what factors will influence their adherence to screening advice and their individual decisions on whether to have prophylactic mastectomy (PM) and/or bilateral prophylactic salpingo-oophorectomy (BPSO). Such information can be used to optimize the advice given on self- or clinicalexamination, to urge women to adhere to the advice given, and to provide support regarding a decision to undergo prophylactic surgery.

This review systematically summarizes the published empirical data describing the predictors of adhering to screening practices and choosing to have prophylactic surgery in women at increased risk for breast and ovarian cancer.

\section{Methods}

\section{Search strategy}

We searched Pubmed, Psychinfo and Cinahl to identify relevant articles published in English between 1990 and June 2006 The following search terms were combined: prophylactic treatment, cancer concern, adherence, compliance, breast cancer, ovarian cancer, BRCA*, uncertainty, psychological, cancer screening, screening behavi*, surveillance, risk perception and genetic risk. Additional sources of articles were references cited in identified papers.

\section{Selection of eligible papers}

All the abstracts identified by the search were assessed by two of the authors independently and any discrepancies were discussed. The selected full articles were independently coded for eligibility by two raters using data extraction sheets. The two raters agreed on the articles to include in the study. Papers were only included if they covered women with a family history of breast or ovarian cancer and a clearly described elevated cancer risk, and if they were empirical studies on:

(1) predictors of breast and ovarian cancer screening

(2) predictors of the use of PM and BPSO

We excluded abstracts of presentations, book chapters, single-page comments, papers about pre-symptomatic DNA-testing, predictors or decisions of genetic testing, intentions to have genetic testing, intentions to have screening and prophylactic treatment, or genetic screening, and reviews, case reports about patients or families, community studies about the use of screening practices, and studies with a purely qualitative study design.

Papers eligible for this review are presented separately with regard to breast or ovarian cancer screening practices and the choice for prophylactic surgery, and are ranked as much as possible by the risk status of the participating women. Only significant predictors are described. Studies concerning participants who were tested for a BRCA mutation, or who had a family history indicative for a BRCA mutation (e.g. at least 2 FDRs with breast or ovarian cancer) were viewed as covering a high-risk population. Studies concerning participants with at least one FDR with a diagnosis of breast or ovarian cancer were viewed as covering a population at moderately increased risk (e.g. cumulative life-time risk of breast cancer $<30 \%$, and of ovarian cancer $<10 \%$ ).

\section{Results}

Using the specific search terms, we identified 37 articles meeting the inclusion criteria (Tables 1-3). Twenty of the 37 selected studies used a prospective design with a followup between 6 months and 5 years, although most of the studies had a follow-up of 1 year or less.

Participants were mainly unaffected women at moderately increased risk for breast and/or ovarian cancer. The study population consisted completely or largely of breast cancer patients in only three studies $[19,50,51]$, whereas in two other studies a small proportion of the participants had a prior history of breast cancer [31, 32]. BRCA mutation carriers were included in 11 studies $[7,19,28,33$, $36,46,49,50,51,58,59]$.

Predictors of the adherence to screening for breast cancer

Twenty-five studies examined possible predictors of adherence to breast cancer screening (Table 1) and screening behavior: in particular, the influence of being a BRCA1/2 mutation carrier $[7,28,33,46]$, of 


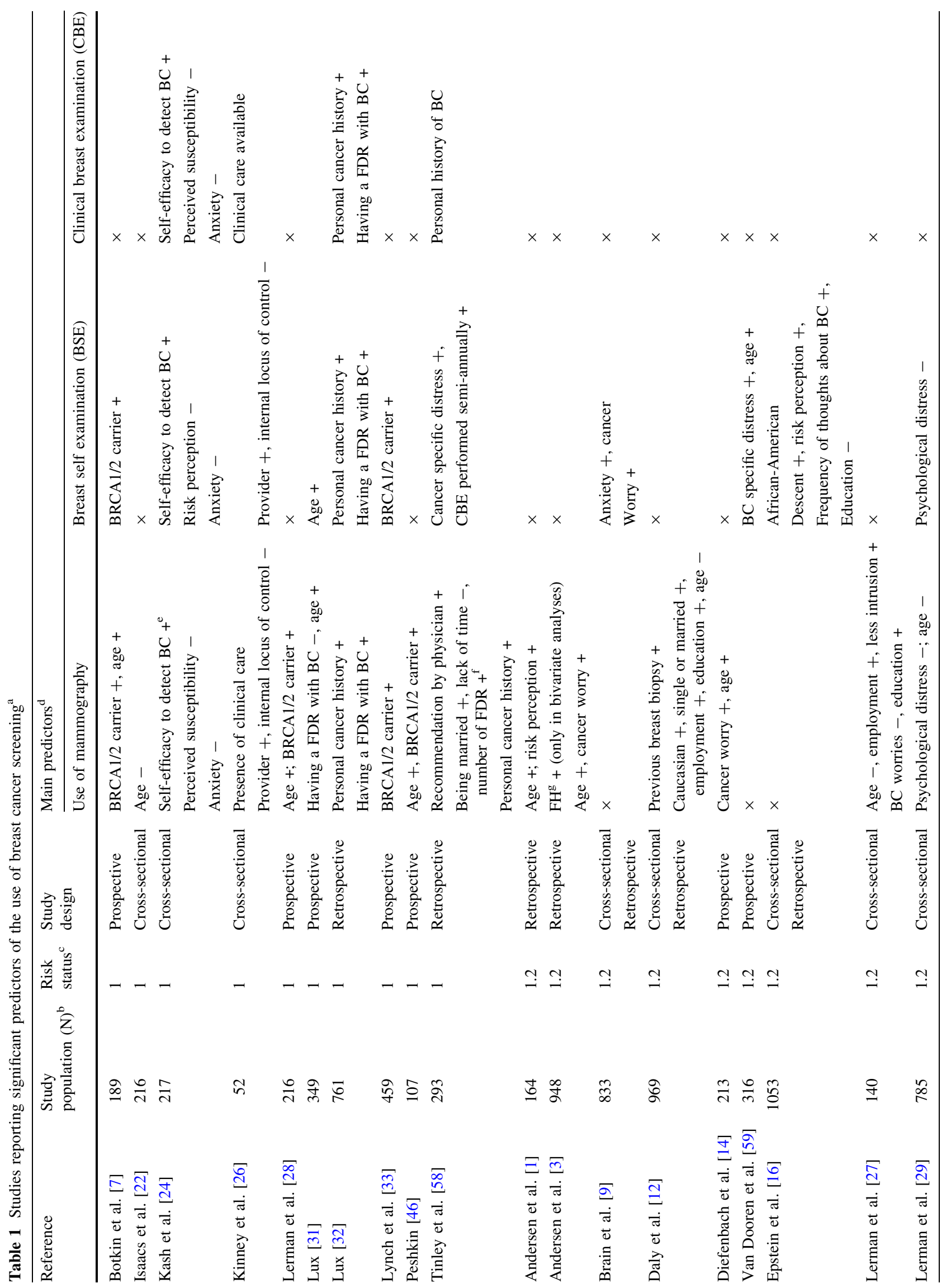




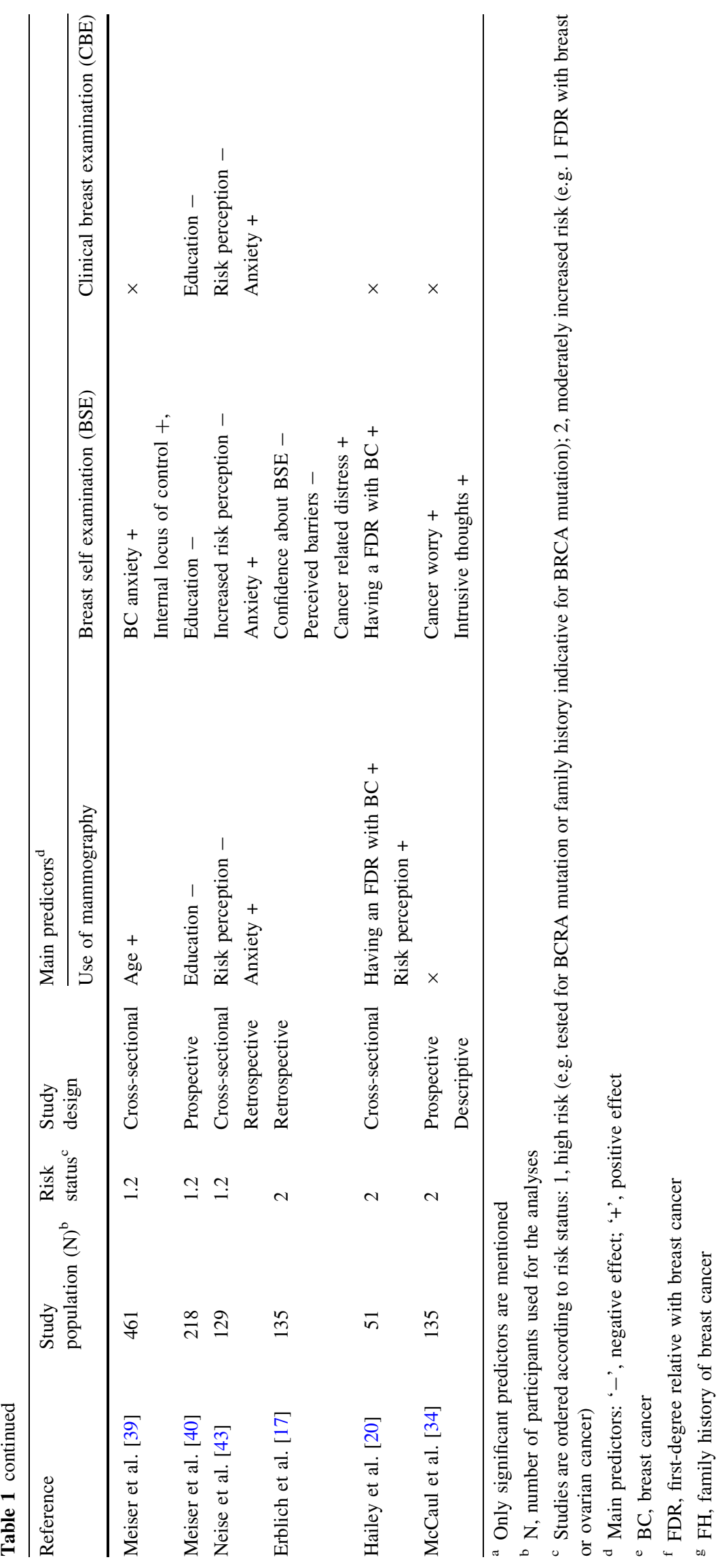


Table 2 Studies reporting significant predictors of the use of ovarian cancer screening ${ }^{\mathrm{a}}$

\begin{tabular}{|c|c|c|c|c|c|}
\hline \multirow[t]{2}{*}{ Reference } & \multirow{2}{*}{$\begin{array}{l}\text { Study } \\
\text { population }(\mathrm{N})^{\mathrm{b}}\end{array}$} & \multirow{2}{*}{$\begin{array}{l}\text { Risk } \\
\text { status }^{c}\end{array}$} & \multirow[t]{2}{*}{ Study design } & \multicolumn{2}{|l|}{ Main predictors $^{\mathrm{d}}$} \\
\hline & & & & Use of CA125 & Ultrasound use \\
\hline Isaacs et al. [22] & 216 & 1 & Cross-sectional & $\begin{array}{l}\mathrm{FH}^{\mathrm{e}}+; \text { Jewish ancestry }+ \\
\text { Risk perception and } \\
\quad \text { objective } \mathrm{OC}^{\mathrm{f}} \text { risk }+\end{array}$ & $\begin{array}{l}\mathrm{FH}+; \text { risk perception }+ \\
\text { Jewish ancestry }+\end{array}$ \\
\hline Tinley et al. [58] & 293 & 1 & Retrospective & $\times$ & $\begin{array}{l}\text { Recommendation by physician }+ \text {, risk } \\
\text { perception }+ \text {, education }+ \text {, support }+\end{array}$ \\
\hline Andersen et al. [1] & 164 & 1.2 & Retrospective & $x$ & $x$ \\
\hline Andersen et al. [2] & 286 & 1.2 & Cross-sectional & FH +; cancer worry + & $x$ \\
\hline Lynch et al. [33] & 459 & 1 & Prospective & BRCA1/2 carrier + & BRCA1/2 carrier + \\
\hline Meiser et al. [38] & 95 & 1.2 & Cross-sectional & $x$ & Age,$+>2$ affected relatives + \\
\hline Schwartz et al. [50] & 289 & 1.2 & Prospective & $\begin{array}{l}\text { BRCA } 1 / 2 \text { carrier }+ \text { risk } \\
\text { perception }+ \text { personal } \\
\text { history } \mathrm{BC}++^{\mathrm{g}}\end{array}$ & Risk perception + \\
\hline Schwartz et al. [52] & 121 & 1.2 & Cross-sectional & $\mathrm{FH}+$, cancer worry + & Employment status + , cancer worry + \\
\hline
\end{tabular}

${ }^{a}$ Only significant predictors are mentioned

${ }^{\mathrm{b}} \mathrm{N}$, number of participants used for the analyses

c Studies are ordered according to risk status: 1, high risk (e.g. tested for BCRA mutation or family history indicative for BRCA mutation); 2 , moderately increased risk (e.g. 1 FDR with breast or ovarian cancer

d '-', negative effect; '+', positive effect

${ }^{\mathrm{e}} \mathrm{FH}$, family history of ovarian cancer

${ }^{\mathrm{f}} \mathrm{OC}$, Ovarian cancer

g BC, Breast cancer

socio-demographic and psychological variables like risk perception, psychological distress, coping strategies [26], and worry about cancer [1, 9, 14, 22, 27, 34].

\section{Socio-demographic variables}

Age There are inconsistent results regarding the influence of age on adherence to screening practices for breast cancer. Some studies found a higher adherence to mammography screening in older women $[1,14,29,32$, $39,46,59]$, whereas other studies showed older women to have a lower adherence [12, 22, 39].

In a prospective study to determine the level of participation to cancer surveillance before and after genetic counseling, Lux et al. [32] found that older women at high risk for breast cancer, more frequently participated in selfpalpation, breast ultrasound and mammography prior to consultation. After consultation, high risk women more frequently used breast ultrasound and mammography. They also found that older women with lower risk more frequently used mammography before and after consultation [32].

In their prospective study, Peshkin et al. [46] examined the use of breast cancer screening in a clinically based sample of 107 women after BRCA1/2 testing. They showed that only $39 \%$ of a younger group of carriers (25-39 years) had mammography compared to $74 \%$ of a group of carriers who were older than 40 years. Factors independently associated with mammography use included age (older than 40 years) and DNA test result. Non-carriers had very good adherence to general population screening guidelines.

In studies of women at moderate risk for breast cancer, Lerman et al. [29] found that age was associated with better adherence to mammography using a cross-sectional and a prospective design [28]. In a longitudinal study in 213 unaffected women, Diefenbach [14] studied the relationship between psychological variables at baseline and subsequent screening behavior. Cancer worry and older age were significant predictors of mammography adherence.

Four studies found a negative association between age and adherence to screening for breast cancer [12, 17, 22, 41]. In a cross-sectional study of 216 unaffected women with a strong family history of breast cancer, Isaacs et al. [22] found that both younger (40-) and older women (50+) had mammography performed less frequently. Meiser et al. [39] found older women (30+) to be more vigilant with respect to mammography recommendations than younger women. Erblich et al. (2000) found a younger age to be associated with underperformance of breast self-examination (BSE) [17]. In a cross-sectional study of a group of women at moderate risk for breast cancer, Daly et al. [12] found that there was a greater disparity between objective risk factors and screening behavior in women older than 50 years.

Civil Status In two studies, civil status has been shown to be associated with better adherence to screening 
Table 3 Studies reporting significant predictors of the use of prophylactic treatments

\begin{tabular}{|c|c|c|c|c|c|}
\hline \multirow[t]{2}{*}{ Reference } & \multirow{2}{*}{$\begin{array}{l}\text { Study } \\
\text { population } \\
\text { (N) }\end{array}$} & \multirow{2}{*}{$\begin{array}{l}\text { Risk } \\
\text { status }^{\text {a }}\end{array}$} & \multirow[t]{2}{*}{ Study design } & \multicolumn{2}{|l|}{ Main predictors ${ }^{\mathrm{b}}$} \\
\hline & & & & Prophylactic mastectomy (PM) & $\begin{array}{l}\text { Bilateral Prophylactic } \\
\text { salpingo oophorectomy } \\
\text { (BPSO) }\end{array}$ \\
\hline Botkin et al. [7] & 189 & 1 & Prospective & & BRCA1/2 carrier + \\
\hline Evans et al. [19] & 158 & 1 & Retrospective & Tumor stage + , having a FDR with $\mathrm{BC}+$ & \\
\hline Lerman et al. [28] & 216 & 1 & Prospective & BRCA1/2 carrier - & BRCA1/2 carrier - \\
\hline Scheuer et al. [49] & 251 & 1 & $\begin{array}{l}\text { Prospective } \\
\text { Descriptive }\end{array}$ & $\begin{array}{l}\text { Age - } \\
\mathrm{FH}+{ }^{\mathrm{c}}\end{array}$ & $\begin{array}{l}\text { Age }+, \\
\text { Personal history } \mathrm{BC}+{ }^{\mathrm{d}}\end{array}$ \\
\hline Schwartz et al. [51] & 79 & 1 & Prospective & $\begin{array}{l}\text { BRCA } 1 / 2 \text { carrier }+ \text {, physicians } \\
\text { recommendations }+\end{array}$ & Risk perception + \\
\hline Meijers-Heijboer et al. [36] & 68 & 1 & Prospective & $\begin{array}{l}\text { BRCA1/2 carrier }+ \\
\text { Parenthood }+, \text { age }-\end{array}$ & $\begin{array}{l}\text { Being a carrier }+ \\
\text { Age }+\end{array}$ \\
\hline Antill et al. [4] & 182 & 1.2 & Retrospective & $\begin{array}{l}\text { Number of relatives died from } \mathrm{BC}+\text {, perceived } \\
\text { cancer risk }- \text {, age }-, \text { BRCA1/2 carrier }+ \\
\text { FH }+ \text {, fibrocystic breasts }+\end{array}$ & Perceived cancer risk - \\
\hline Meiser et al. [38] & 95 & 1.2 & Cross sectional & Cancer worry + & Cancer anxiety + \\
\hline Stefanek et al. [55] & 164 & 1.2 & Prospective & $\begin{array}{l}\text { Cancer worry }+ \text {, risk perception }+ \text {, } \\
\text { previous breast biopsy }+\end{array}$ & \\
\hline Schwartz et al. [51] & 289 & 1.2 & Prospective & & $\mathrm{FH}+$ \\
\hline Tiller et al. [57] & 95 & 1.2 & Prospective & & Attitude + , age + \\
\hline
\end{tabular}

practices [12, 58]. Tinley et al. found being married was associated with adherence to mammography guidelines [58], while Daly found being either married or single were associated with adherence to mammography [12] compared to being divorced or widowed.

Education In several studies about predictors of breast cancer screening, higher education is related to higher mammography adherence [12, 27]. However, Meiser et al. [40] found lower education to be associated to more vigilance to screening practices (mammography, BSE and clinical breast examination) in a group of 218 unaffected women who were at increased risk for breast cancer. A lower level of education was also found to be associated to excessive breast self-examination [16].

\section{Disease-related variables}

Family history of breast cancer Several studies showed that having a family history of breast cancer was associated with better adherence to mammography[3, 20, 31, 58]. Studying the influence of familial risk on the age of uptake of early cancer detection facilities, Lux et al. [31] found that patients without breast cancer participated at an earlier time in all methods of early cancer detection than patients with a history of breast cancer. They concluded that familial risk can influence patient's behaviour in relation to early cancer detection facilities and result in a younger age of uptake of nearly all methods of early cancer detection facilities.

In bivariate analyses, Andersen et al. found that family history was a significant predictor of mammography use in a large cross-sectional study. However, it did not remain significant after adjusting for age and worry [3]. Prospective study designs have shown being a carrier of a BRCA1/2 mutation to be associated with better adherence to mammography and BSE [7, 28].

Lynch et al. [33] evaluated the adherence to cancer prevention recommendations in women with known BRCA mutations before and after BRCA mutation disclosure. They found that the rate of compliance with both breast and ovarian cancer screening recommendations was significantly increased among mutation carriers following result disclosure. Among noncarriers, the rate of compliance with breast cancer screening was significantly increased.

Risk perception Risk perception (e.g. the perception of one's own risk of developing breast cancer) has often been studied in association with adherence to screening for breast cancer. The results are not unequivocal, with some studies showing a positive association [16, 20, 32], two 
studies showing a negative association [24, 43], and other studies finding no relationship [3, 12, 52].

In three studies, a positive association was found between risk perception and adherence to screening practices for breast cancer. Hailey et al. [20] examined the impact of having a first degree relative (FDR) with breast cancer on women who were not involved in a formal breast cancer prevention program. Women with a FDR had more negative attitudes about breast cancer (including more anxiety) than women without a FDR, thought they had a greater risk of getting breast cancer (although they underestimated their true risk), and were more likely to engage in appropriate screening behavior. A higher perceived risk of breast cancer was associated with better mammography use for all women, regardless of whether they had a FDR.

In a large cross-sectional study of 1053 unaffected women with at least one FDR with breast cancer, Epstein et al. [16] examined which demographic and psychological factors were associated with excessive BSE performance. Excessive BSE was more common in older women of African-American descent, who were less well educated and more likely to have an affected daughter and more than 2 affected FDRs. Ethnicity, perceived risk of breast cancer, and frequency of thoughts about breast cancer were also independently significantly associated with excessive BSE. They concluded that women identified as excessive selfexaminers should be educated about the proper frequency of BSE and told that more frequent practice does not improve the efficacy of this technique.

In the studies by Kash et al. [24] and Neise et al. [43], a negative association was found between risk perception and adherence to screening practices. Kash et al. [24] studied the beliefs of women at high risk for breast cancer about their risk of getting breast cancer and the impact of this information on their surveillance behaviors and psychological distress. However, women with a sense of personal efficacy regarding early detection of breast cancer also engaged more frequently in general preventive health care behaviors. Women who perceived their risk as high, were more anxious, felt they could do little about developing breast cancer, and were less compliant with surveillance and other preventive behaviors. Being at high risk may not be a reason to start surveillance behaviors, but may in fact increase a woman's fears and thus act as a deterrent. Kash et al. [24] found negative linear relationships between anxiety and BSE, and between perceived risk and BSE [24].

In a study among 129 women with a moderate family history of breast cancer, Neise et al. [43] found that the majority of women either over-estimated (52\%) or underestimated (24\%) their personal risk despite prior genetic counseling. Women who thought they had a high risk underwent the recommended screening significantly less often than women with a low risk perception. Daly et al. [12] and Andersen et al. [1] did not find any association between risk perception and screening practices. In a crosssectional study, Daly et al. [12] examined the relationship between the accuracy of the perceived risk and prior breast cancer screening behavior in a group of 969 women with a moderate risk for breast cancer: reported mammography adherence was only associated with having had a breast biopsy.

Andersen et al. [1] performed a study to examine the association between the perception of high risk for ovarian cancer and the use of breast and ovarian cancer-screening. They found that rates of mammography screening were low among women with a high or average risk perception. Although women with a high risk perception reported high levels of awareness of breast cancer, this did not spur them to undergo additional screening.

Several studies showed over-performance of BSE to be associated with more breast cancer specific distress [17, 59], though it is not possible to say whether there is a specific causal relationship between over-performance of BSE and distress.

\section{Psychological variables}

Worry about cancer Some studies found cancer worry to be associated with better adherence to screening recommendations [3, 9, 14, 34], but Isaacs' study [22] of 216 unaffected women with a strong family history of cancer found no association. In a study on mammography screening in a cohort of 140 FDRs of breast cancer patients [27], it was shown that worrying about breast cancer may form a barrier to mammography adherence among highrisk women, particularly those with less formal education.

In a cross-sectional study, Andersen et al. [1] examined the association of worry about breast cancer with mammography use in a large population-based sample stratified on family history of breast cancer. In bivariate analyses, family history proved to be a significant predictor of mammography use. However, in the multivariate analyses it was not significant after adjusting for age and worry, which did remain as significant predictors for mammography [3].

McCaul et al. [34] performed a prospective, longitudinal study about breast cancer worry in 135 women with a moderate family history. Women with a positive family history reported more frequent worrying and distress than those without. Baseline worry and intrusive thoughts were positively associated with self-reported BSE behavior, but trait anxiety did not predict BSE behavior.

Anxiety Anxiety level has been found to be associated with both more $[9,17,39,43,59]$ and less adherence to BSE and clinical breast examination [24, 29], but another 
study found no influence of anxiety on adherence to screening practices [7].

The studies of Kash et al. [24] and Lerman et al. [29] found a negative association between anxiety and screening adherence. In Kash et al.'s [24] cross-sectional study, women who perceived their risk as high, had high anxiety, felt they could do little about developing breast cancer, and were less compliant with BSE, clinical breast examination, and other preventive behavior. They concluded that being at high risk may increase a woman's fears and thereby deter surveillance behavior [24].

In a cross-sectional study, Lerman et al. [29] found that younger women with a moderate family history of breast cancer less frequently adhered to BSE and about one-third of all women reported breast cancer worries. Psychological distress was associated with non-adherence to mammography, and with both infrequent and excessive BSE [29].

In a prospective study among 189 women at high risk for breast cancer, Botkin et al. [7] did not find an association of general and test-specific anxiety with mammography adherence among mutation carriers at 2 years posttesting.

In all the other studies mentioned, there was a positive association found between anxiety and screening adherence. In a cross-sectional study of 461 unaffected women with a moderate risk for breast cancer, Meiser et al. [39] examined breast cancer screening uptake and vigilance to breast cancer screening recommendations and its sociodemographic and psychosocial predictors. It was shown that women's psychological characteristics (Internal Health Locus of Control and Anxiety) were more powerful predictors of BSE than objective breast cancer risk and sociodemographic characters.

Brain et al. [9] examined the relationship between anxiety and adherence to breast self-examination in a group of 833 women with a moderate risk for breast cancer. In their retrospective study they found that higher levels of cancer-specific anxiety were associated with higher rather than lower BSE frequency. This seemed to be a function of greater subjective concern rather than more extensive family history. They also found that excessive self-examiners reported higher general anxiety. In a study among 129 women with a moderate family history, Neise et al. [43] found that highly anxious women showed above-average participation in screening programs.

Erblich et al. [17] found that over-performers of BSE reported more cancer-related distress (intrusive breast cancer thoughts and emotional upset during BSE) than regular BSE performers and underperformers. In a prospective design, Van Dooren et al. [59] found breast cancer specific distress to be associated with BSE over-performance in women younger than 40 years.
Predictors of the use of screening for ovarian cancer

Eight studies investigated predictors of ovarian cancer screening and these are summarized in Table 2. The main predictors are being a carrier of a BRCA1/2 mutation [33, 50], perceived risk $[1,22]$ cancer worries $[2,22,52]$, age $[32,38]$, the number of affected relatives [22, 38], employment status [52] and Jewish ancestry [22].

Among carriers of a BRCA mutation, there was an increased rate of compliance to ovarian cancer screening compared to non-carriers [33] and women who received a negative or uninformative DNA test result [50].

Isaacs et al. [22] performed a cross-sectional study in 216 unaffected women with a strong family history of breast or ovarian cancer who were participating in a free BRCA genetic counseling and testing program. They found that only $20 \%$ of participants had ever had a CA-125 measurement performed, while $31 \%$ had had a pelvic or abdominal ovarian ultrasound examination. Women with a family history of ovarian cancer were much more likely to undergo ovarian cancer screening. In their study, the perceived and objective risks were independent predictors of CA-125 measurements. They also found a positive association with Jewish ancestry and screening practices for ovarian cancer, while having at least one relative with ovarian cancer was strongly associated with ovarian cancer screening. There were no associations between screening behavior and cancer worries, or the number of relatives with breast cancer, or income. They concluded that breastand ovarian-screening uptake in healthy women from hereditary breast cancer families is suboptimal. Their findings indicate a need for better education about screening guidelines for high-risk women.

Andersen et al. [2] examined the association between the perception of high risk for ovarian cancer and the interest in the use of breast and ovarian cancer-screening. High-risk women reported low levels of awareness of ovarian cancer, so that ovarian cancer screening was seriously under-used.

A study of female FDRs of patients with ovarian cancer, showed that the use of ovarian cancer screening among women at moderate risk was positively influenced by the number of affected relatives, as well as by psychological (cancer worries) and socio-demographic factors (employment status) [52].

Both Isaacs et al. [22] and Meiser et al. [38] found a positive association between the number of relatives with ovarian cancer and the screening uptake for ovarian cancer. Meiser et al. [38] studied 95 unaffected women with a moderate family history of breast or ovarian cancer who had not had a DNA test: women with 2 or more affected relatives were more likely to have ovarian ultrasound tests than women with less than 2 affected relatives. 
Predictors of the use of prophylactic mastectomy

Predictors for prophylactic surgery are summarized in Table 3. Indicators for choosing a (contralateral) prophylactic mastectomy $((\mathrm{C}) \mathrm{PM})$ are being a carrier of a BRCA1/2 mutation [4, 19, 51], physician's advice [51], elevated cancer anxiety [38, 55], parenthood [36], and number of affected relatives [4, 49].

Being a mutation carrier was significantly related to patients' surgical decision-making. Schwartz et al. [51] studied a group of 194 newly diagnosed breast cancer patients for the impact of genetic counseling and testing on their surgical decision-making. In their study, $48 \%$ of the identified carriers chose bilateral prophylactic mastectomy (BPM) in contrast with only $24 \%$ of the patients in whom no mutation was detected. Evans et al. [19] found that contralateral breast cancer risk at the time of diagnosis was the clearest indicator for choice to have risk reducing CPM. They suggest that all women in the highest risk categories should have the option of discussing the contralateral risk, genetic testing and their options regarding surgery at the time of their initial breast cancer diagnosis.

However, others show that unaffected carriers may not opt for prophylactic surgery as only $3 \%$ of the unaffected carriers had had a mastectomy one year after their test result had been disclosed [28].

Young women with children opt for DNA testing and PM especially, so that parenthood is a predictor of prophylactic mastectomy [36].

Additional predictors of bilateral mastectomy included patients' self-reports of physician recommendations for BRCA1/2 testing and BPM [51].

Several studies showed that elevated cancer worry or cancer anxiety had a positive influence on opting for surgery [38, 55]. Stefanek et al. [55] indicated that breast cancer related worry may influence the selection for PM in women $(\mathrm{N}=164)$ with an elevated risk (at least one FDR with breast cancer). Women who did not express interest in surgery reported fewer biopsies and a lower subjective breast cancer risk.

Antill et al. [4] found a significant association between the uptake of BPM and number of relatives who had died from breast cancer. Women who reported BPM gave a lower estimation of their own cancer risk than those who had not undertaken the procedure.

Predictors of the use of prophylactic salpingo-oophorectomy

Factors other than anxiety are more powerful predictors for the uptake of bilateral prophylactic salpingo-oophorectomy (BPSO) in women with a strong family history (more than two FDRs) with breast or ovarian cancer. Women's attitude about BPSO is a significant and useful indicator of actual uptake, as is age. No significant association between cancer worry and uptake was found, although anxiety was significantly reduced after BPSO and women expressed a high level of satisfaction with their decision [57].

There is a tendency among women to opt for a BPSO rather than a BPM $[7,28,36]$. In a prospective study ( $\mathrm{N}=500,2$ years follow-up) by Botkin et al. [7], the response to interventions for early cancer prevention in mutation carriers, non-carriers and women who did not have a DNA test were compared. None of the carriers had had a BPM 2 years after testing. Of carriers who were 25 years and older, $46 \%$ had obtained BPSO (including $78 \%$ of the women 40 years and older). Carriers preferred prophylactic surgery to reduce their ovarian cancer risk to other early detection measures.

In a study by Meijers-Heijboer et al. [36], $51 \%$ of 68 unaffected women with an identified mutation who were eligible for prophylactic surgery opted for bilateral mastectomy and $64 \%$ opted for BPSO. Age was significantly associated with BPSO (older women were more likely to opt for BPSO than younger women), but not with mastectomy, although there was a tendency towards choosing mastectomy at a younger age. Antill et al. [4] also showed that women over 40 years and mutation carriers more frequently chose for BPSO.

In the study by Lerman et al. [28] $13 \%$ of the carriers had had a BPSO one year after learning of their test result and $4.4 \%$ had chosen for BPM.

Scheuer et al. [49] found similar results. In a sample of 251 mutation carriers, women with PM were younger than those not opting for surgery. Apart from that, women who did not undergo preventive surgery showed an overall increase in screening behavior. Women who opted for BPSO had a stronger family history of ovarian cancer or had a greater number of first- and second-degree relatives with a prior breast cancer diagnosis.

Meiser et al. [38] demonstrated that women with high cancer anxiety were significantly more likely to consider BPSO. In a group of unaffected women with a strong family history of breast and ovarian cancer ( $\mathrm{N}=95$, no DNA test), $12 \%$ had undergone a BPSO and $23 \%$ said they would consider it if genetic testing indicated a mutation. The consideration was positively related with increased levels of cancer anxiety, but not with objective risk.

In a study by Schwartz et al. [50] among 297 high-risk women who were offered free genetic counseling and testing, having BPSO was independently predicted by perceived (elevated) risk of ovarian cancer, and by a family history of ovarian cancer: $27 \%$ of the mutation carriers and $2 \%$ of the non-carriers had BPSO in the year following their testing. 


\section{Discussion}

The empirical studies covered in this review reveal several predictors of the use of breast/ovarian cancer screening and (contralateral) prophylactic mastectomy and bilateral salpingo-oophorectomy ((C)PM, BPSO). The main predictors are related to DNA test results, socio-demographic characteristics, and psychological outcome measures. Knowledge about the influence of these predictors may help physicians in giving patient tailored information about screening practices and the options of prophylactic surgery.

\section{Screening for cancer}

Several factors may influence a patient's decision to start regular surveillance. As expected, DNA test results predict the use of screening. Among BRCA1/2 carriers there was an increased use of CA-125, transvaginal ultrasound screening, and mammography $[7,46,50]$. BSE (breast selfexamination) also increased in mutation carriers [7]. Uninformative or negative DNA test results do not lead to increased ovarian cancer screening. However, non-carriers may increase the frequency of their mammography screens and BSE if recommendations for the general population are discussed during genetic counseling, which suggests that they are not falsely reassured by a negative genetic test result [7, 46]. Apparently, good adherence to general population screening guidelines can be achieved in women from high-risk families who appear to be negative for the BRCA mutation. When genetic testing is completed, clinicians and geneticists could therefore be invited to discuss the breast cancer screening recommendations for the general population with the non-carriers.

It has recently been shown that surveillance for ovarian cancer in women at high-risk has important limitations and is very inefficient $[35,44]$. For now, BPSO remains the optimal risk-reducing strategy for women at high risk. This implies that nowadays screening for ovarian cancer will not be advocated in many hospitals, so uptake will vary in different centres regardless of other variables.

In most studies selected for this review, cancer worry and anxiety are positively related to breast and ovarian cancer screening practices, suggesting that worry and anxiety are not a barrier to using screening [2, 9, 14, 17, 34, 41, 43, 50, $52,58]$. In a meta-analysis about the relationship between worry and screening behaviours Hay et al, concluded that in most studies breast cancer worry is associated with a greater likelihood of screening [21]. This conclusion holds regardless of how cancer worry is measured and whether the screening outcome was mammography or BSE. They also found that high levels of cancer worry are uncommon and high levels of worry were not associated with reduced screening. However, others have demonstrated that higher anxiety was related to poor adherence to BSE and clinical breast examination [24], particularly in women with less formal education [30]. It can be concluded that in daily clinical practice, clinicians should check whether women at risk for breast/ovarian cancer have a high level of anxiety as this may lead to suboptimal screening. It would be useful to reduce the level of anxiety in these women.

Age seems to be an independent factor associated with the use of screening. Mutation carriers younger than 40 years had a mammogram made less often than older carriers (over 40 years) [7, 46]. In unaffected women at a moderately increased risk for breast cancer and in whom no DNA test was performed, the younger women also adhered less to the mammography recommendations [3, 14, 29, 39]. On the other hand, others have reported that rates of adherence to mammography were lower in women over 50 years $[12,22,30]$.

Perceived risk is a predictor of both ovarian cancer screening [22, 50, 58] and breast cancer screening [1, 3, 16], although women who perceived their risk as high were less compliant with breast cancer screening recommendations [24, 43]. Although risk perception decreases after genetic counseling, it is often still over-estimated, especially by cancer patients [47]. As this may affect screening practices, efforts should be made to improve a patient's risk perception.

Family history predicts ovarian cancer screening [2, 22, 38 , 52], but is related less to breast cancer screening $[3,20]$. This may be because ovarian cancer more often has a fatal prognosis, which could motivate women to take preventive measures.

Adherence to screening practices is associated with recommendations from physicians [58]. The potential of effective support from primary care physicians could be utilized by involving them more in the surveillance of women at high risk. Recommendations should be explicitly communicated to primary physicians by general education. In addition to training doctors, our findings also indicate a need for better patient education about the screening guidelines for high-risk women.

Prophylactic surgery

A patient's decision to have prophylactic surgery may be influenced by several physical and psychosocial factors. Being a carrier of a BRCA1/2 mutation and the number of affected relatives are major predictors of the decision to have prophylactic surgery [49, 51], although Lerman et al. [28] had opposite findings: the majority of the carriers in their study did not opt for prophylactic surgery. On the other hand, those who opted to have PM often had an inaccurate perception of how high their risk for developing breast cancer was, which emphasizes the importance of 
accurate risk counseling in women with a high risk for breast and ovarian cancer. Cancer worry or anxiety was also found to influence the choice for prophylactic surgery, further underlining the importance of physicians providing adequate information about cancer risk.

The tendency to have BPSO rather than PM may be associated with the greater esthetic consequences of PM. Moreover, women appear to prefer prophylactic surgery more than early detection measures to reduce their risk for ovarian cancer [7]. The fact that age was found to be a strong predictor of oorophorectomy but not for mastectomy may well be associated with future options for childbearing. Furthermore, especially young women with children choose to have DNA testing and PM [36], which may also be associated with subsequent decisions about having children and their desire to see them grow up.

Another factor found to predict prophylactic surgery is the physician's advice and recommendations about it [51]. However, an important predictor of a patient later regretting having had PM is when the physician was the one to introduce this option into the discussion of treatment [6, 45]. This emphasizes that physicians must be well aware of how much they may influence a woman's decision to have prophylactic surgery, and they must remain alert when giving advice about possible treatment and monitoring options and verify whether the choice for prophylactic surgery is based on the patients' own decision.

The uptake rates of PM and BPSO seem to differ between different countries [28, 37]. Several studies suggest cultural differences may also play a role in decision making about prophylactic surgery $[8,18,23]$. Such cultural differences are likely to be caused by different attitudes of women at increased risk and their doctors and substantial differences in the way cancer geneticists deal with prophylactic surgery [8]. The adoption of national guidelines for prophylactic surgery may increase homogeneity in surgery rates from country to country. However, one must be aware of the cultural differences when implementing international guidelines for families at risk for breast and ovarian cancer.

\section{Directions for future research}

Most studies in this review had a retrospective and/or cross-sectional design. Retrospective studies may be biased by memory-bias and response-shift. Cross-sectional designs disallow causal inferences between possible predictors and screening practices and the decision to have prophylactic surgery. Future studies should preferably use a prospective, longitudinal design to determine the predictors of screening behavior and prophylactic surgery. Psychosocial assessment before genetic counseling in women at high risk for breast or ovarian cancer, and at several time-points afterwards, would provide information about changes in women's knowledge, risk perception, cancer worries and distress, for example $[11,53,56]$.

Screening for breast or ovarian cancer in women at risk for these cancers may, in fact, be a burden leading to much distress. Studies eligible for this review differed in their definition of high risk. Most studies defined high risk as having one first-degree relative with breast or ovarian cancer, while a number of studies did not specify what they defined as high risk (and these were not included in the present review). Narod et al. [42] stated that high risk for breast or ovarian cancer should be defined in future studies as having at least two or more first-degree relatives with this kind of cancer and/or being a mutation carrier. Many studies selected for this review concerned women with a moderate risk for breast or ovarian cancer, with only a few studies covering women who were carriers of a BRCA mutation. Future studies should therefore include only women with a high risk for breast or ovarian cancer and/or women who are mutation carriers.

Acknowledgements This study was supported by a grant from the Dutch Cancer Society. Many thanks to dr Jackie Senior for her accurate suggestions regarding the English text of our manuscript.

Open Access This article is distributed under the terms of the Creative Commons Attribution Noncommercial License which permits any noncommercial use, distribution, and reproduction in any medium, provided the original author(s) and source are credited.

\section{References}

1. Andersen MR, Bowen D, Yasui Y, McTiernan A (2003) Awareness and concern about ovarian cancer among women at risk because of a family history of breast or ovarian cancer. Am J Obstet Gynecol 189:42-47

2. Andersen MR, Peacock S, Nelson J, Wilson S, McIntosh M, Drescher C et al (2002) Worry about ovarian cancer risk and use of ovarian cancer screening by women at risk for ovarian cancer. Gynecol Oncol 85:3-8

3. Andersen MR, Smith R, Meischke H, Bowen D, Urban N (2003) Breast cancer worry and mammography use by women with and without a family history in a population-based sample. Cancer Epidemiol Biomarkers Prev 12:314-320

4. Antill Y, Reynolds JC, Young MA, Kirk J, Tucker K, Bogtstra T et al (2006) Risk-reducing surgery in women with familial susceptibility for breast and/or ovarian cancer. Eur J Cancer 42: 621-628

5. Antoniou A, Pharoah PD, Narod S, Risch HA, Eyfjord JE, Hopper JL et al (2003) Average risks of breast and ovarian cancer associated with BRCA1 or BRCA2 mutations detected in case Series unselected for family history: a combined analysis of 22 studies. Am J Hum Genet 72:1117-1130

6. Borgen PI, Hill AD, Tran KN, Van Zee KJ, Massie MJ, Payne D et al (1998) Patient regrets after bilateral prophylactic mastectomy. Ann Surg Oncol 5:603-606

7. Botkin JR, Smith KR, Croyle RT, Baty BJ, Wylie JE, Dutson D et al (2003) Genetic testing for a BRCA1 mutation, prophylactic 
surgery and screening behavior in women 2 years post testing. Am J Med Genet 118A:201-209

8. Bouchard L, Blancquaert I, Eisinger F, Foulkes WD, Evans G, Sobol $\mathrm{H}$ et al (2004) Prevention and genetic testing for breast cancer: variations in medical decisions. Soc Sci Med 58: 1085-1096

9. Brain K, Norman P, Gray J, Mansel R (1999) Anxiety and adherence to breast self-examination in women with a family history of breast cancer. Psychosom Med 61:181-187

10. Burke W, Daly M, Garber J, Botkin J, Kahn MJ, Lynch P et al (1997) Recommendations for follow-up care of individuals with an inherited predisposition to cancer. II. BRCA1 and BRCA2 Cancer Genetics Studies Consortium. JAMA 277:997-1003

11. Cella D, Hughes C, Peterman A, Chang C, Peshkin BN, Schwartz MD et al (2002) A brief assessment of concerns associated with genetic testing for cancer, the Multidimensional Impact of Cancer Risk Assessment (MICRA) Questionnaire. Health Psychol 21:564-572

12. Daly MB, Lerman CL, Ross E, Schwartz MD, Sands CB, Masny A (1996) Gail model breast cancer risk components are poor predictors of risk perception and screening behavior. Breast Cancer Res Treat 41:59-70

13. De Waard F, Collette HJ, Rombach JJ, Baanders-van Halewijn EA, Honing C (1984) The DOM project for the early detection of breast cancer, Utrecht, The Netherlands. J Chronic Dis 37:1-44

14. Diefenbach MA, Miller SM, Daly MB (1999) Specific worry about breast cancer predicts mammography use in women at risk for breast and ovarian cancer. Health Psychol 18:532-536

15. Eisen A, Rebbeck TR, Wood WC, Weber BL (2000) Prophylactic surgery in women with a hereditary predisposition to breast and ovarian cancer. J Clin Oncol 18:1980-1995

16. Epstein SA, Lin TH, Audrain J, Stefanek M, Rimer B, Lerman C (1997) Excessive breast self-examination among first-degree relatives of newly diagnosed breast cancer patients. High-risk breast cancer consortium. Psychosomatics 38:253-261

17. Erblich J, Bovbjerg D, Heiddis B, Valdimarsdottir H (2000) Psychological distress, health beliefs, and frequency of breast self-examination. J Behav Med 23:277-292

18. Evans DG, Anderson E, Lalloo F, Vasen HF, Beckman M, Eccles D (1999) Utilization of prophylactic mastectomy in 10 European centres. Dis Markers 15:148-151

19. Evans D, Lalloo F, Hopwood P, Maurice A, Baildam A, Brain A et al (2005) Surgical decisions made by 158 women with hereditary breast cancer aged $<50$ years. Eur J Surg Oncol 31:1112-1118

20. Hailey BJ, Carter CL, Burnett DR (2000) Breast cancer attitudes, knowledge, and screening behavior in women with and without a family history of breast cancer. Health Care Women Int 21:701-715

21. Hay J, McCaul KD, Magnan R (2006) Does worry about breast cancer predict screening behaviors? A meta-analysis of the prospective evidence. Prev Med 42:401-408

22. Isaacs C, Peshkin BN, Schwartz M, DeMarco TA, Main D, Lerman C (2002) Breast and ovarian cancer screening practices in healthy women with a strong family history of breast or ovarian cancer. Breast Cancer Res Treat 71:103-112

23. Julian-Reynier CM, Bouchard LJ, Evans DG, Eisinger FA, Foulkes WD, Kerr B et al (2001) Women's attitudes toward preventive strategies for hereditary breast or ovarian carcinoma differ from one country to another: differences among English, French, and Canadian women. Cancer 92:959-968

24. Kash KM, Holland JC, Halper MS, Miller DG (1992) Psychological distress and surveillance behaviors of women with a family history of breast cancer. J Natl Cancer Inst 84:24-30

25. King ES, Resch N, Rimer B, Lerman C, Boyce A, McGovernGorchov P (1993) Breast cancer screening practices among retirement community women. Prev Med 22:1-19
26. Kinney AY, Emery G, Dudley WN, Croyle RT (2002) Screening behaviors among African American women at high risk for breast cancer: do beliefs about God matter? Oncol Nurs Forum 29: $835-843$

27. Lerman C, Daly M, Sands C, Balshem A, Lustbader E, Heggan T et al (1993) Mammography adherence and psychological distress among women at risk for breast cancer. J Natl Cancer Inst 85:1074-1080

28. Lerman C, Hughes C, Croyle RT, Main D, Durham C, Snyder C et al (2000) Prophylactic surgery decisions and surveillance practices one year following BRCA1/2 testing. Prev Med 31:75-80

29. Lerman C, Kash K, Stefanek M (1994) Younger women at increased risk for breast cancer: perceived risk, psychological well-being, and surveillance behavior. J Natl Cancer Inst Monogr:171-176

30. Lerman C, Schwartz M (1993) Adherence and psychological adjustment among women at high risk for breast cancer. Breast Cancer Res Treat 28:145-155

31. Lux m, Ackermann S, Bani M, Nestle-Kramling C, Goecke T, Niederacher D et al (2005) Age of uptake of early cancer detection facilities by low-risk and high-risk patients with familial breast and ovarian cancer. Eur J Cancer Prev 14:503-511

32. Lux m, Ackermann S, Nestle-Kramling C, Goecke T, Niederacher D, Bodden-heidrich R et al (2005) Use of intensified early cancer detection in high-risk patients with familial breast and ovarian cancer. Eur J Cancer Prev 14:399-411

33. Lynch HT, Snyder C, Lynch J, Karatoprakli P, Trowonou A, Metcalfe K et al (2006) Patient responses to the disclosure of BRCA mutation tests in hereditary breast-ovarian cancer families. Can Genet Cytogen 165:91-97

34. McCaul KD, Branstetter AD, O'Donnell SM, Jacobson K, Quinlan KB (1998) A descriptive study of breast cancer worry. J Behav Med 21:565-579

35. Meeuwissen PA, Seynaeve C, Brekelmans CT, Meijers-Heijboer HJ, Klijn JG, Burger CW (2005) Outcome of surveillance and prophylactic salpingo-oophorectomy in asymptomatic women at high risk for ovarian cancer. Gynecol Oncol 97:476-482

36. Meijers-Heijboer EJ, Verhoog LC, Brekelmans CT, Seynaeve C, Tilanus-Linthorst MM, Wagner A et al (2000) Presymptomatic DNA testing and prophylactic surgery in families with a BRCA1 or BRCA2 mutation. Lancet 355:2015-2020

37. Meijers-Heijboer H, van-Geel B, van-Putten WLJ, Henzen-Logmans SC, Seynaeve C, Menke-Pluymers MBE et al (2001) Breast cancer after prophylactic bilateral mastectomy in women with a BRCA1 or BRCA2 mutation. N Engl J Med 345:159-164

38. Meiser B, Butow P, Barratt A, Friedlander M, Gattas M, Kirk J et al (1999) Attitudes toward prophylactic oophorectomy and screening utilization in women at increased risk of developing hereditary breast/ovarian cancer. Gynecol Oncol 75:122-129

39. Meiser B, Butow P, Barratt A, Friedlander M, Kirk J, Gaff C et al (2000) Breast cancer screening uptake in women at increased risk of developing hereditary breast cancer. Breast Cancer Res Treat 59:101-111

40. Meiser B, Butow PN, Barratt AL, Schnieden V, Gattas M, Kirk J et al (2001) Long-term outcomes of genetic counseling in women at increased risk of developing hereditary breast cancer. Patient Educ Couns 44:215-225

41. Meiser B, Tiller K, Gleeson MA, Andrews L, Robertson G, Tucker KM (2000) Psychological impact of prophylactic oophorectomy in women at increased risk for ovarian cancer. Psychooncology 9:496-503

42. Narod SA, Offit K (2005) Prevention and management of hereditary breast cancer. J Clin Oncol 23:1656-1663

43. Neise C, Rauchfuss M, Paepke S, Beier K, Lichtenegger W (2001) Risk perception and psychological strain in women with a family history of breast cancer. Onkologie 24:470-475 
44. Oei AL, Massuger LF, Bulten J, Ligtenberg MJ, Hoogerbrugge N, de Hullu JA (2006) Surveillance of women at high risk for hereditary ovarian cancer is inefficient. Br J Cancer 94:814-819

45. Payne DK, Biggs C, Tran KN, Borgen PI, Massie MJ (2000) Women's regrets after bilateral prophylactic mastectomy. Ann Surg Oncol 7:150-154

46. Peshkin BN, Schwartz MD, Isaacs C, Hughes C, Main D, Lerman C (2002) Utilization of breast cancer screening in a clinically based sample of women after BRCA1/2 testing. Cancer Epidemiol Biomarkers Prev 11:1115-1118

47. Pieterse AH, Ausems MG, Van Dulmen AM, Beemer FA, Bensing JM (2005) Initial cancer genetic counseling consultation, change in counselees' cognitions and anxiety, and association with addressing their needs and preferences. Am J Med Genet 137:27-35

48. Sattin RW, Rubin GL, Webster LA, Huezo CM, Wingo PA, Ory HW et al (1985) Family history and the risk of breast cancer. JAMA 253:1908-1913

49. Scheuer L, Kauff N, Robson M, Kelly B, Barakat R, Satagopan J et al (2002) Outcome of preventive surgery and screening for breast and ovarian cancer in BRCA mutation carriers. J Clin Oncol 20:1260-1268

50. Schwartz MD, Kaufman E, Peshkin BN, Isaacs C, Hughes C, Demarco T et al (2003) Bilateral prophylactic oophorectomy and ovarian cancer screening following BRCA1/BRCA2 mutation testing. J Clin Oncol 21:4034-4041

51. Schwartz MD, Lerman C, Brogan B, Peshkin BN, Halbert $\mathrm{CH}$, Demarco $T$ et al (2004) Impact of BRCA1/BRCA2 counseling and testing on newly diagnosed breast cancer patients. J Clin Oncol 22:1823-1829
52. Schwartz M, Lerman C, Daly M, Audrain J, Masny A, Griffith K (1995) Utilization of ovarian cancer screening by women at increased risk. Cancer Epidemiol Biomarkers Prev 4:269-273

53. Schwartz MD, Peshkin BN, Hughes $C$, Main D, Isaacs $C$, Lerman C (2002) Impact of BRCA1/BRCA2 mutation testing on psychologic distress in a clinic-based sample. J Clin Oncol 20: 514-520

54. Slattery ML, Kerber RA (1993) A comprehensive evaluation of family history and breast cancer risk. The Utah Population Database. JAMA 270:1563-1568

55. Stefanek ME, Helzlsouer KJ, Wilcox PM, Houn F (1995) Predictors of and satisfaction with bilateral prophylactic mastectomy. Prev Med 24:412-419

56. Tercyak KP, Lerman C, Peshkin BN, Hughes C, Main D, Isaacs C et al (2001) Effects of coping style and BRCA1 and BRCA2 test results on anxiety among women participating in genetic counseling and testing for breast and ovarian cancer risk. Health Psychol 20:217-222

57. Tiller K, Meiser B, Butow P, Clifton M, Thewes B, Friedlander $M$ et al (2002) Psychological impact of prophylactic oophorectomy in women at increased risk of developing ovarian cancer: a prospective study. Gynecol Oncol 86:212-219

58. Tinley ST, Houfek J, Watson P, Wenzel L, Clark MB, Coughlin S et al (2004) Screening adherence in BRCA1/2 families is associated with primary physicians' behavior. Am J Med Genet 125A:5-11

59. Van Dooren S, Rijnsburger A, Seynaeve C, Kriege A, Duivenvoorden H, Bartels C et al (2003) Psychological distress and breast self examination frequency in women at increased risk for hereditary or familial breast cancer. Commun Genet 6:235-241 